MPIDR Working Paper WP 2021-010 I May 2021

https://doi.org/10.4054/MPIDR-WP-2021-010

\title{
Birth cohort changes in fertility ideals: Evidence from repeated cross-sectional surveys in Finland
}

\author{
Kateryna Savelieva I kateryna.savelieva@helsinki.fi \\ Natalie Nitsche I nitsche@demogr.mpg.de \\ Venla Berg \\ Anneli Miettinen \\ Anna Rotkirch \\ Markus Jokela
}

\footnotetext{
This working paper has been approved for release by: Mine Kühn (kuehn@demogr.mpg.de), Deputy Head of the Laboratory of Population Health.

(c) Copyright is held by the authors.
} 


\section{Birth cohort changes in fertility ideals: Evidence from repeated cross- sectional surveys in Finland}

Kateryna Savelieva ${ }^{1,2^{*}}$, Natalie Nitsche ${ }^{3}$, Venla Berg ${ }^{4,5}$, Anneli Miettinen ${ }^{6}$, Anna Rotkirch ${ }^{4}$, Markus Jokela ${ }^{2}$

${ }^{1}$ Helsinki Collegium for Advanced Studies, University of Helsinki, Finland

${ }^{2}$ Department of Psychology and Logopedics, Faculty of Medicine, University of Helsinki, Finland

${ }^{3}$ Max-Planck Institute for Demographic Research, Rostock, Germany

${ }^{4}$ Population Research Institute, Väestöliitto, Finland

${ }^{5}$ Institute of Criminology and Legal Policy, University of Helsinki, Finland

${ }^{6}$ Kela, the Social Insurance Institution of Finland, Finland

* Corresponding author: Helsinki Collegium for Advanced Studies, University of Helsinki, P.O. Box 4 (Fabianinkatu 24), 00014 University of Helsinki, Finland. E-mail:

kateryna.savelieva@helsinki.fi, tel. +358504075216.

Acknowledgements: Kateryna Savelieva was supported by the Helsinki Collegium for Advanced Studies at the University of Helsinki and the Finnish Cultural Foundation (under grant 00200993). Data collection was supported by the Alli Paasikivi Foundation.

Data Availability: The data used are available to registered users from the Finnish Social Science Data Archive (https://services.fsd.tuni.fi/catalogue/series/14?tab=studies\&lang=en).

Conflict of Interest: The authors declare no conflicts of interest. 


\begin{abstract}
Since the great recession, fertility has been declining steeply in some high-income countries. It is, however, unknown whether the ideal number of children, a key predictor of fertility behaviour, has also declined, either in parallel or prior to fertility decline. Finland is known for its supportive family policies, but is among those countries, which have experienced drastic and poorly understood fertility decline over the last decade. Using repeated crosssectional survey data from the Finnish Family Barometers, we examined birth cohort changes in ideal number of children among men and women born in 1970-94. Our findings indicate that the ideal number of children was lower among more recent compared to earlier birth cohorts. This difference in fertility ideals was driven by larger proportions of those preferring to remain childless among the recent birth cohorts. This suggests that attitudes of Finns towards childbearing have changed and may contribute to recent fertility decline.
\end{abstract}

Keywords: fertility, ideal number of children, birth cohort changes, parenthood status, partnership status, education. 


\section{Introduction}

Fertility ideals and desires are among the key predictors for childbearing behaviour (Bongaarts 2001; Miller 2011; Philipov and Bernardi 2012). However, over the life course, ideas about one's ideal family size are competing with other life goals and are subjected to a variety of social and economic constraints (Lutz et al. 2006; Philipov and Bernardi 2012). Hence, several studies have shown that people in high-income countries are more likely to underachieve their fertility ideals than to overachieve them (Beaujouan and Berghammer 2019; Harknett and Hartnett 2014; Morgan and Rackin 2010). On the aggregate level, some studies have demonstrated that a two-child family ideal has been persistent in most European countries and in the US over the last three decades (Hagewen and Morgan 2005; Sobotka and Beaujouan 2014), suggesting that the ideal number of children has stabilized around the replacement level. Fertility rates, however, have been declining to well-below replacement levels in most high-income countries today (Sobotka 2020). This macro-level disparity between ideal and achieved average family size has been described as a 'fertility gap' (Philipov 2009).

Yet, there is some evidence that fertility ideals are declining as well (Goldstein et al. 2003; Hagewen and Morgan 2005; Testa 2007). Drawing on the Eurobarometer 2001 survey for 15 European countries, Goldstein and colleagues (2003) showed that the personal ideal number of children is below the replacement level in Germany and Austria, especially for young people 20-34-year-olds when compared to 35-49-year-olds. These findings were further confirmed by Testa (2007) using data from the Eurobarometer 2006 survey. In line with these studies, Hagewen and Morgan (2005) have used US survey data to show that there might be a decline in the intended number of children for young women under 25 years. Likewise, a recent study by Hartnett and Gemmill (2020) showed that the intended number of children has declined in the US from 2006 to 2017, and childlessness intentions among younger people have risen. This period was also characterized by unprecedented declines in the total fertility rate in the US (Rybińska 2020).

Declining fertility ideals may thus be among the underlying factors contributing to the recent fertility decline in developed countries. According to the secod demographic transition theory (SDT), ideational factors and value changes play a crucial role in family formation in contemporary developed societies, since strict marital and social norms as determinants of childbearing have been replaced by individual choices (Lesthaeghe 2010, 2014). Currently, the spread of post-materialist or postmodern values, such as the need for self-actualization, self-development, and consumption/leisure aspirations, are related to a decreased importance 
of having children compared to other life goals (Lesthaeghe 2014). At the same time, the cost of childbearing in terms of financial resources and time investments has increased (Craig et al. 2014; Kornrich and Furstenberg 2013). Due to the high expectations of good parenting (the so-called intensive parenting), younger people might perceive childbearing as more demanding than their parents' generation (Craig et al. 2014). This may, in turn, be related to the increase in childfree preferences among younger people (Rybińska 2020), and to the increased ideal age at first birth (Melnikas and Romero 2020). To continue, broader societal changes, often classified under the umbrella of globalization, and the rise of new information channels, including social media, are related to rising uncertainty in people's life and, as a result, may lead to changes in family formation and may shape the aspirations of young adults (Mills and Blossfeld 2013; Vignoli et al. 2020). Finally, according to the low fertility trap hypothesis (Lutz et al. 2006), the ideal family size for the more recent birth cohorts declines as a consequence of low actual fertility rates they see in previous birth cohorts.

Taking all this into account, it is, therefore, possible that younger people from more recent birth cohorts have lower fertility ideals compared to people born earlier, but no previous studies have investigated birth cohort effects in the ideal number of children. One reason for this is the lack of available data that would comprise information on fertility ideals from several birth cohorts asked at approximately same ages. Sobotka and Beaujouan (2014) showed time period effects in fertility ideals but did not examine birth cohort effects. Thus, it remains unclear whether people born more recently have lower ideal number of children compared to people born earlier. The birth cohort effects might also be observed in how socio-demographic factors related to fertility behaviour (e.g., age, education, parenthood status, and partnership status) are associated with the ideal number of children. Identifying these birth cohort associations might help to better identify the social factors that underlie the declining fertility rates. The present study focuses on the birth cohort effects in the ideal number of children in Finland.

\section{Background}

Ideal number of children (also referred to as ideal family size) is usually conceptualized as the best number of children a person would have with perfect fertility control and without constraints on having children (Liu and Lummaa 2019; Philipov and Bernardi 2012; Thomson 2015). Ideal number of children can concern the population at large (e.g., 'What would be an ideal number of children for a family?') and in that case can be interpreted as societal norms (Philipov and Bernardi 2012). In the present study, we focus on 
personal ideal number of children, the concept which in previous literature has often been used synonymously with fertility desires (i.e., usually measured by asking how many children people wish to have) (see for example Philipov and Bernardi 2012; Testa 2007, 2012).

Attitudes towards children are central for forming personal ideal family size, which result in the desire to have children when partner's attitudes are taken into account (Liu and Lummaa 2019). Fertility desires, in turn, determine intentions of having children (i.e., represent what one actually plans to do regarding childbearing), which are realized within the constraints of life circumstances (Liu and Lummaa 2019). Fertility ideals and desires are considered more abstract concepts reflecting one's attitudes and wishes about having children, whereas fertility intentions are viewed as more concrete plans regarding childbearing. Previous studies examining changes in the general or personal ideal number of children have mainly focused on investigating changes during time periods (e.g., Hagewen and Morgan 2005; Sobotka and Beaujouan 2014) or over the life course (e.g., Gray et al. 2013; Heiland et al. 2008; Kuhnt et al. 2017), and less is known about birth cohort effects on changes in ideal number of children.

In addition to asking whether fertility ideals are changing across cohorts, it is also important to understand why they are changing, and which groups are more likely to change their ideals. Previous studies investigating life course changes in the ideal or desired number of children have shown that fertility ideals and desires are declining with age, especially among women (Gray et al. 2013; Heiland et al. 2008; Kuhnt et al. 2017). Childbearing itself can change personal ideal number of children, such that the birth of a child leads to increased fertility ideals (Heiland et al. 2008; Kuhnt et al. 2017). Partnership dissolution also seems to affect the desired number of children (Gray et al. 2013), but not necessarily the ideal number of children (Kuhnt et al. 2017). Education also matters for ideal number of children: more highly educated women prefer to have larger families compared to less educated women (Kuhnt et al. 2017; Morgan and Rackin 2010; Testa 2012), but at the same time they are also more likely to underachieve their fertility ideals and desires (Berrington and Pattaro 2014; Morgan and Rackin 2010; Nitsche and Hayford 2020). To our knowledge, no studies have examined the role of these socio-demographic factors in birth cohort changes of ideal number of children.

\section{The Finnish context}

Since 2010, the total fertility rate (TFR) has been steeply declining in Finland from 1.87 births in 2010 to 1.35 in 2019 (Statistics Finland 2020); in 2020, the decrease stagnated. 
Similar trends have been observed in other Nordic countries, although these declines have been less pronounced than in Finland (Hellstrand et al. 2020a). The tempo-adjusted TFR has also been decreasing in Finland during the last decade, indicating that the fall in TFR is not fully explained by postponement of childbearing to later ages (Hellstrand et al. 2020b). The decomposition of birth order showed that the decreasing first births accounted for more than $75 \%$ of the decline in period fertility, followed by $21 \%$ decline in second and third births (Hellstrand et al. 2020b). At the same time, the share of childless women at the age of 50 has increased from $13.6 \%$ in 1989 to $19.6 \%$ in 2016 (Roustaei et al. 2019).

Currently, there is no consensus regarding the reasons for such steep fertility decline (Hiilamo 2020; Rotkirch et al. 2017). One reason could be that the fertility ideals of Finns, especially among young people, are declining (Rotkirch 2020). Preliminary survey results suggest that the ideal number of children have changed over the last 20 years (Berg 2018; Miettinen 2015a; Rotkirch et al. 2017). However, it is not known whether there are birth cohort effects in personal ideal number of children.

\section{Present study}

The present study used repeated cross-sectional data from Finland from 2007 to 2018 to examine birth cohort effects in the personal ideal number of children among people born between 1970 and 1994. Fertility has been declining among women of all age groups and different parities, but the decline of first-order births, especially among women under 30 years of age, has made the largest contribution (Hellstrand et al. 2020b). We examined the differences in ideal number of children across birth cohorts in the whole sample and separately among childless people and parents. Based on the low fertility trap hypothesis, as well as evidence from the previous studies showing that ideal number of children is below replacement level especially for more recent cohorts (Goldstein et al. 2003; Hagewen and Morgan 2005; Testa 2007), we hypothesised that personal ideal number of children will be lower for more recent cohorts compared to earlier cohorts. We further investigated whether the previously identified socio-demographic characteristics (age, parenthood status, partnership status, and education) play a role for change in ideal number of children across birth cohorts. We pose no hypothesis regarding the birth cohort effects in the associations between age, partnership status, and education with ideal number of children. Although our study does not examine associations between changes in the ideal number of children and actual fertility rates in Finland, studying change in fertility ideals per se is important as it can 
serve as an indicator of broader cultural changes that might occur in family formation in Finland.

\section{Methods}

Sample

Data came from six waves of the repeated cross-sectional Family Barometer surveys (2007-2018), conducted by Väestöliitto, the Finnish Family Federation, to study various topics related to family life and childbearing in Finland (Lainiala et al. 2014; Miettinen, 2015b; Miettinen and Rotkirch, 2008a, 2010). The surveys in 2007 and 2008 were conducted as postal surveys by the Population Research Institute at Väestöliitto, and the surveys in 2010, 2014, 2015, and 2018 were conducted as online surveys by KANTAR TNS Gallup Oyj. The response rates for postal surveys were 52\% in 2007 and $44 \%$ for 2008, whereas the response rates for online surveys cannot be determined. The participants for the online surveys were recruited by KANTAR TNS Gallup Oyj from the panel of participants of approximately 50000 households, which represent Finnish population (excluding the Aland islands). The sample size for the online surveys was predetermined, and the data collection was finished once the sample size was reached.

The total sample comprised 14,667 participants (1,560-3,180 participants per survey year). For this study, we included only men and women aged 20-45 who reported their ideal number of children. Thus, the analytical sample included 7,444 participants with 493-2057 participants per survey year.

\section{Measures}

Ideal number of children was self-reported in all surveys and coded as 0, 1, 2, 3+ children. It was asked with the following questions: "The ideal number of children in my own family would be ..." in survey 2007; "The ideal number of children for yourself would be..." in survey 2008; and "What is or would have been your own ideal number of children?" in surveys 2010-2018. Birth cohorts were the following: 1970-74, 1975-79, 1980-84, 198589, 1990-94. Age was used as a continuous variable and centred at 20 years to facilitate the interpretation of the results. Gender was coded as $0=$ male and $1=$ female. Parenthood status was coded as $0=$ childless and $1=$ one or more children. Partnership status was coded as $0=$

single, widowed, divorced, or separated and $1=$ married, cohabiting, or being in a registered partnership. Education was coded as $0=$ basic, $1=$ secondary, $2=$ lower tertiary, and $3=$ upper tertiary. 


\section{Statistical analysis}

By pooling data from six survey years, we examined birth cohort changes in ideal number of children using random-intercept linear regression analysis, with survey year as a random intercept. To examine the overall birth cohort change in fertility ideals, we first conducted the analyses in the whole sample separately for men and women. We then examined birth cohort changes separately for childless people and parents, because there were changes between cohorts in age at first birth, proportion of people remaining childless, and further, the age effects on ideal number of children were different for parents and childless people. Given that the decline of first-order births has made the largest contribution to decline in TFR in Finland (Hellstrand et al. 2020b), we focused on childless people and further examined the probability of their childfree ideals (i.e., desiring 0 children) using random-intercept logistic regression analysis, as well as mean ideal number of children among the subset of those childless people who want to have children (ideal number of children >0) using random-intercept linear regression analysis. When conducting analyses in the childless sample, we restricted the sample to people aged 20-35 because older childless people are more likely to have higher childfree ideals compared to younger childless people, due to being selected into childlessness based on childfree preferences, and due to downward adjustments in the ideal number of children among those who remained childless involuntary (Miettinen et al. 2015c). When assessing birth cohort effects, age was modelled with linear and quadratic terms, and birth cohort as a categorical variable. To illustrate these associations, we plotted adjusted predictions of the mean ideal number of children at different ages for each birth cohort.

To assess how the associations of age, parenthood status, partnership status, and education with ideal number of children differ by birth cohort, we examined the interaction effects of birth cohort with the abovementioned variables in separate models. For these analyses, we restricted our sample to participants aged 20-35 and excluded participants from the earliest birth cohort (i.e., 1970-74) to make birth cohorts more comparable and focus only on those still at risk of childbearing. To aid the interpretation of the coefficients, age was divided by 5 , so that a one-unit increase in age on ideal number of children corresponds to 5 years when reporting the unstandardized regression coefficients. Education was divided by 3 , so that the one-unit difference corresponds to change from basic to upper tertiary education.

All statistical analyses were conducted in Stata 15 (StataCorp 2017). 


\section{Results}

\section{Characteristics of the sample}

Table 1 shows the characteristics of the sample. The mean age of participants was 32.2 years, and there were 4459 (59.9\%) women and 2985 men. About half of the sample were childless (56.5\% for men and 53.6\% for women), and the proportion of childless people versus parents by birth cohorts and age groups is shown in Supplementary Table 1. Women were more often in a steady relationship compared to men $(68.0 \%$ vs. $63.8 \%, \mathrm{p}<0.001)$ and were more educated (e.g., $23.3 \%$ vs. $20.1 \%$ for higher tertiary education, $\mathrm{p}<0.001$ ). There were no differences in mean ideal number of children between men and women $(\mathrm{p}=0.305)$. Almost half of the participants had an ideal of two children $(51.2 \%$ for men and $44.9 \%$ for women), $27.2 \%$ had an ideal of three children (24.4\% for men and $29.2 \%$ for women), $15.2 \%$ had childfree ideals ( $14.7 \%$ for men and $15.5 \%$ for women), and finally $10.2 \%$ listed one child as an ideal (9.8\% for men and $10.4 \%$ for women).

\section{Changes in ideal number of children across birth cohorts}

Figure 1 shows the mean ideal number of children at different ages for birth cohorts separately for men and women. The more recent cohorts have a lower ideal number of children compared to the earlier cohorts. These associations were especially pronounced among women (Supplementary Table 2). For example, at age 30, the mean ideal number of children for women born in 1980-84 and 1985-89 was 1.9 and 1.8, respectively, and significantly lower than the mean ideal of 2.3 and 2.2 for women born in 1970-74 and 197579 , respectively. The differences in the mean ideal number of children were largest until age 30 and then decreased gradually. The results were similar for men, even though the interaction effects between age and birth cohort were mostly nonsignificant (Supplementary Table 2). In the combined sample of men and women, the results were similar to those for women (see Supplementary Fig. 1), and the three-way interactions between age, cohort, and gender were nonsignificant (all p-values > 0.301), suggesting that the birth cohort effects did not differ between men and women.

We further examined birth cohort effects the in ideal number of children among childless people and parents (Figure 2). The trend was similar between childless and parents - the more recent cohorts reported a lower ideal number of children compared to the earlier cohorts. Compared to the total sample, the associations between age and ideal number of children by birth cohort were attenuated by about a half when examined only among parents, and the ideal number of children did not drop below two, as many of the parents already had 
two children (Figure 2, Supplementary Table 3). For childless people, the associations look more similar to the total sample, but the ideal number of children decreased below two for more recent birth cohorts. Similar to the total sample, the differences in mean ideal number of children were largest until age 30 and then decreased gradually (Figure 2).

We then examined whether the decline in ideal number of children among younger birth cohorts was either driven by an increase in childfree ideals or by decreases in the average ideal number of children among those who desired to have at least one child. When analysing childfree ideals, we focused on childless people, because the proportion of parents who stated childfree ideals was very low in all birth cohorts $(0-2.3 \%$, except for male parents from the 1990-94 birth cohort who were on average considerably young when becoming parents $-11.6 \%$; Supplementary Table 4). There were significant main effects of birth cohort, as well as interactions between age and birth cohort on the probability of childfree preferences: younger childless men and women in more recent cohorts had higher probability of childfree preferences compared to earlier cohorts (Figure 3A, Supplementary Table 5). In contrast, there were no main effects of birth cohort on ideal number of children, and no interactions between age and birth cohort on ideal number of children among people who wanted to have children (Figure 3B, Supplementary Table 6). Although there was a trend for lower fertility ideals in younger compared to older cohorts also among respondents who did want to have children (Figure 3B), these differences in fertility ideals were not significant across birth cohorts. Overall, these findings suggest that increases in childfree preferences among more recent birth cohorts compared to earlier ones seem to drive the overall decline in average fertility ideals across cohorts.

Associations of age, parenthood status, partnership status, and education with changes in ideal number of children across birth cohorts

Figure 4 shows how the associations of ideal number of children with age, parenthood status, partnership status, and education differed by birth cohorts. Fertility ideals declined with age for both men and women in all birth cohorts (Figure 4, Supplementary Table 7 for parameter estimates), but the decline was stronger in older cohorts. This was partly related to a higher initial ideal number of children in older compared to younger cohorts (floor effects among younger cohorts), but could also reflect changes in normative ideals in the age at first (or last) birth. Being a parent was related to a higher ideal number of children in all birth cohorts, whereas having a partner was related to a higher ideal number of children among men and women in more recent but not in earlier birth cohorts (Figure 4, 
Supplementary Table 7). Higher education was associated with a higher ideal number of children among women, especially in earlier birth cohorts, but not among those born in 1990-94. In contrast, for men higher education was related to a higher ideal number of children especially among those born in 1990-94 (Figure 4, Supplementary Table 7). Finally, the three-way interactions between birth cohorts, gender, and the socio-demographic variables of interest were non-significant (all p-values $<0.05$ ).

\section{Discussion}

This study examined birth cohort effects in the ideal number of children among men and women born in 1970-1994 using repeated cross-sectional surveys from Finland. In line with our expectations of declining fertility ideals among more recent birth cohort, we found that more recent birth cohorts had a lower mean ideal number of children compared to earlier birth cohorts, especially among women. A similar trend was observed when analysing childless people and parents separately. This finding could not be explained by declining ideals for large families among those who wanted to have at least one child, as there were not birth cohort differences for ideal number of children among those who wanted to become parents. Instead, there was an increase in the ideal of remaining childless among the more recent birth cohorts. The ideal number of children declined with age in all birth cohorts, and being a parent was related to having a higher ideal number of children in all birth cohorts. Also, people in a steady relationship had a higher average ideal number of children, but this was observed only for younger cohorts. Finally, higher education was associated with a higher ideal number of children among women, especially in earlier birth cohorts.

Consistent with previous studies showing that the personal ideal number of children is below replacement level especially for younger cohorts in Germany and Austria (Goldstein et al. 2003; Testa 2007), we also observed that fertility ideals in Finland have become much lower for more recent cohorts compared to the earlier cohorts when examined at the same ages. For example, compared to the people born in 1970-75, those born in 1985-89 desired on average 0.56 children less at age 30 . At the same time, our findings are in contrast to Sobotka and Beaujouan (2014) main results showing that the mean ideal family size of two children has been persistent in most European countries over the last three decades. They did, however, show that the proportion of women with an ideal of 3 or more children has declined over time, whereas the proportion of women expressing an ideal of 0 or 1 child has increased in Europe. It should be noted that our study cannot be strictly compared to Sobotka and Beaujouan (2014) study, which examined changes in ideal number of children reported in 
general and over time periods, whereas we investigated changes in personal ideal number of children and over birth cohorts.

Given that the decline of first-order births contributed the most to the decline in period fertility in Finland (Hellstrand et al. 2020b), we further examined differences in mean ideal number of children over birth cohorts among childless people and parents. A similar pattern was observed among childless and parents: people from more recent birth cohorts had lower mean ideal number of children. These associations were especially pronounced among childless people: the mean ideal number of children for people born in 1985-89 and 1990-94 cohorts was below the replacement level of 2.1 and much lower (1.8 and 1.7, respectively) compared to 2.1 and 2.6 for people born in 1980-84 and 1975-79 cohorts, respectively. We also found that the decline in fertility ideals is likely to be driven by the increased childfree ideals among childless people from more recent birth cohorts (19\% and 20\% for men born in 1985-89 and 1990-94, respectively, compared to 4\% and 7\% for men born in 1975-79 and 1980-84, respectively; the corresponding percentages for women were 18 and $21 \%$ compared to $4 \%$ and $10 \%$ ). Among parents, we found that very few people stated that their ideal number of children is zero. Thus, the increase in childfree ideals rests solely on those still childless and does not reflect increasing levels of frustration with being a parent among those who do have children.

Age at first birth has continuously increased among recent birth cohorts (Statistics Finland 2020) and we can thus assume that our sub-sample of childless individuals is less selected on the desire to become a parent among the most recent birth cohorts, at least at ages below 30. As the average age at first birth in Finland is currently at 29.6 years (Statistics Finland 2020), many of those will likely still make the transition to parenthood as they age. Hence, in the absence of change in fertility ideals, people who are still childless would be expected to have slightly higher average fertility ideals among more recent cohorts, because they should be less selected on the desire to remain childless. In other words, our estimates of increases in childfree ideals among the recent birth cohorts, in particular below the age of 30 , most likely reflect a lower bound of the actual change and serve as strong evidence for significant declines in the average ideal number of children. Our findings thus contribute to the recent evidence about the rise of childlessness intentions among young people, as demonstrated for the US (Hartnett and Gemmill 2020).

We also found that the ideal number of children decreases with age in all birth cohorts. This accords with previous studies which investigated life course changes in ideal (and desired) number of children and showed that fertility ideals decline with age, especially 
among women (Gray et al. 2013; Heiland et al. 2008; Kuhnt et al. 2017). In our study, the decline in ideal number of children with age was much steeper for earlier cohorts compared to the more recent cohorts. This could be explained by the true decline in ideal number of children, given that the earlier cohorts had a higher ideal number of children to begin with or by changes in normative ideals on age restrictions for the age at first birth. To continue, we also found that parenthood status was related to higher ideal number of children in all birth cohorts. Our findings are in line with previous longitudinal studies on changes in ideal (and desired) number of children and suggest that childbearing itself can change personal ideal number of children and usually leads to increased fertility ideals (Gray et al. 2013; Heiland et al. 2008; Kuhnt et al. 2017).

Another finding was a higher ideal number of children among people in steady relationships. However, these associations were only observed for more recent cohorts, whereas partnership status seems not to be related to fertility ideals among earlier cohorts. This could suggest an increasing selectivity into partnerships based on fertility ideals over birth cohorts; in other words, fewer individuals in more recent birth cohorts may opt for steady relationship, namely only those who are more family oriented to begin with. However, the reverse is also possible: being in steady relationships may increase personal ideal number of children. When we additionally examined whether the probability of having a partner has declined in younger cohorts, this trend was indeed observed. The number of people in stable relationships is lower among more recent birth cohorts after adjusting for age (see Supplementary Figure 2), however, these associations were nonsignificant in our data.

We also found that higher education was related to higher ideal number of children, especially among women from earlier birth cohorts, but not anymore among those born in 1990-94. These results are in line with the recent evidence from Finland suggesting that decline in fertility rates was not as pronounced in men and women of higher socioeconomic status compared to people of lower socioeconomic status, as measured in both lower total period fertility (Statistics Finland 2020) and completed fertility (Jalovaara et al. 2018). These findings are also in accordance with previous studies, which have reported that higher educated women prefer to have larger families compared to less educated women (e.g., Kuhnt et al. 2017; Morgan and Rackin 2010; Testa 2012), but no previous study has examined whether this association would differ over birth cohorts. In our study, the associations between education and the ideal number of children were stronger among earlier birth cohorts. 
More broadly, our findings suggest that the attitudes towards childbearing are changing in Finland. Lutz (2020) has suggested that some cultural changes might have been happening in the Nordic countries leading to the decreased ideal family size for younger cohorts, which, in turn, might have contributed to the declining fertility in Finland during the last decade. It has been shown that the ideal number of children has declined over the last 20 years in Finland (Berg 2018; Miettinen 2015a; Rotkirch et al. 2017), and here we demonstrate that fertility ideals are also declining across birth cohorts, with a larger proportion of young people stating zero children as their ideal. One explanation could be that the importance of life goals other than childbearing has increased among young adults, as more people choose to postpone or even renounce childbearing in order to pursue other life goals than parenting (Miettinen 2015a; Rotkirch et al. 2017). Recently, these factors seem to have become more important in postponement of childbearing than economic factors or the lack of a suitable partner (Miettinen 2015a; Rotkirch et al. 2017). This is in line with the second demographic transition theory, which emphasizes the rise of individualist attitudes as one of the reasons for falling fertility (Lesthaeghe 2014). It is also possible that due to the high perceived cost of childbearing and overall uncertainty in the future, more recent generations tend to postpone childbearing, which is reflected in the increased ideal age at first birth among Finns: from 25.6 in 2007 for women (27.4 for men) to 26.7 in 2015 (28.5 for men) (Miettinen 2015a; Miettinen and Rotkirch 2008b). This might be an additional component causing further delays in childbearing, especially of first births, and contribute to the recent fertility decline in Finland.

Some limitations of this study should be acknowledged. First, the phrasing of the questions regarding the ideal number of children differed slightly between the questionnaires used in 2007, 2008, and 2010-2018 surveys. Although all the questions asked about the personal ideal number of children, the different phrasing (e.g., "The ideal number of children in my own family would be..." versus "The ideal number of children for yourself would be...") might resulted in people's different interpretations of this question. However, after repeating the analyses either without data from 2007 survey or 2008 survey, the results remained the same (available upon request from the corresponding author). Second, we did not have data for people born in the earlier cohort (1970-1974) when they were in their 20s, therefore we could not directly compare them to the people from more recent cohorts. Third, it is possible that the selection of participants might differ between the postal surveys (2007 and 2008) and TNS Gallup's online surveys (2010-2018) due to the differences in the data 
collection process, and more family-oriented people may slightly dominate in the postal surveys.

In conclusion, using repeated cross-sectional surveys from Finland, our study shows that the ideal number of children has decreased among more recent birth cohorts compared to earlier birth cohorts, a finding which is mainly driven by birth cohort increases in the ideal of remaining childless. This implies that the attitudes of Finns towards childbearing have changed which might be one of the drivers of fertility decline in Finland. It should be noted that several European countries, as well as the US, have experienced similarly drastic declines in fertility rates in the last decade, which remain equally poorly understood. Cohort changes in fertility ideals have not been studied recently, and our findings suggest potential mechanisms behind this recent fertility change that may be applicable to the other European countries and the US context as well. Future studies should examine whether this change is also occurring in other countries and whether it is more pronounced in Finland than elsewhere. Also, it is crucial to investigate the degree to which the currently observed unprecedented fertility decline in Finland can be attributed to the changes in fertility ideals. Lastly, it would be important to study the reasons for which this change is occurring and whether it translates into actual fertility behaviour. 


\section{References}

Beaujouan, E., \& Berghammer, C. (2019). The gap between lifetime fertility intentions and completed fertility in Europe and the United States: A cohort approach. Population Research and Policy Review, 38(4): 507-535. doi: 10.1007/s11113-019-09516-3

Berg, V. (2018). Touko 2018 Tietovuoto: Suomalaiset haluavat nykyään vähemmän lapsia kuin ennen [Finnish people currently desire less children than before]. Retrieved from http://www.vaestoliitto.fi/tieto_ja_tutkimus/vaestontutkimuslaitos/tietovuodot/touko2018- tietovuoto/

Berrington, A., and Pattaro, S. (2014). Educational differences in fertility desires, intentions and behaviour: A life course perspective. Advances in Life Course Research, 21: 10-27. doi: 10.1016/j.alcr.2013.12.003

Bongaarts, J. (2001). Fertility and reproductive preferences in post-transitional societies. Population and Development Review, 27: 260-281. Retrieved from http://www.jstor.org/stable/3115260

Craig, L., Powell, A., and Smyth, C. (2014). Towards intensive parenting? Changes in the composition and determinants of mothers' and fathers' time with children 1992-2006. The British Journal of Sociology, 65(3): 555-579. doi: 10.1111/1468-4446.12035

Goldstein, J., Lutz, W., and Testa, M. R. (2003). The emergence of sub-replacement family size ideals in Europe. Population Research and Policy Review, 22(5/6): 479-496. doi: 10.1023/B:POPU.0000020962.80895.4a

Gray, E., Evans, A., and Reimondos, A. (2013). Childbearing desires of childless men and women: When are goals adjusted? Advances in Life Course Research, 18(2), 141-149. doi: 10.1016/j.alcr.2012.09.003

Hagewen, K. J., and Morgan, S. P. (2005). Intended and ideal family size in the United States, 1970-2002. Population and Development Review, 31(3): 507-527. doi: 10.1111/j.1728-4457.2005.00081.x

Harknett, K., and Hartnett, C. S. (2014). The gap between births intended and births achieved in 22 European countries, 2004-07. Population Studies, 68(3): 265-282. doi: $10.1080 / 00324728.2014 .899612$

Hartnett, C. S., and Gemmill, A. (2020). Recent trends in U.S. childbearing intentions. Demography, 57(6): 2035-2045. doi: 10.1007/s13524-020-00929-w

Heiland, F., Prskawetz, A., and Sanderson, W. C. (2008). Are individuals' desired family sizes stable? Evidence from West German panel data. European Journal of Population / Revue Européenne de Démographie, 24(2): 129-156. doi: 10.1007/s10680-008-9162-x 
Hellstrand, J., Nisén, J., Miranda, V., Fallesen, P., Dommermuth, L., and Myrskylä, M. (2020a). Not just later, but fewer: Novel trends in cohort fertility in the Nordic countries. Max Plank Demographic Research Institute, Rostock, MPIDR-Working Paper, 7. doi: 10.4054/MPIDR-WP-2020-007

Hellstrand, J., Nisén, J., and Myrskylä, M. (2020b). All-time low period fertility in Finland: Demographic drivers, tempo effects, and cohort implications. Population Studies, 1-15. doi: 10.1080/00324728.2020.1750677

Hiilamo, P. H. (2020). Why fertility has been declining in Finland after the Global Recession? Finnish Yearbook of Population Research, 54: 29-51. doi: 10.23979/fypr.85090

Jalovaara, M., Neyer, G., Andersson, G., Dahlberg, J., Dommermuth, L., Fallesen, P., and Lappegård, T. (2018). Education, gender, and cohort fertility in the Nordic countries. European Journal of Population, 35(3): 563-586. doi: 10.1007/s10680-018-9492-2

Kornrich, S., and Furstenberg, F. (2013). Investing in children: Changes in parental spending on children, 1972-2007. Demography, 50(1): 1-23. doi: 10.1007/s13524-012-0146-4

Kuhnt, A.-K., Kreyenfeld, M., and Trappe, H. (2017). Fertility ideals of women and men across the life course, in M. Kreyenfeld \& D. Konietzka (Eds.), Childlessness in Europe: Contexts, Causes, and Consequences (pp. 235-251). Springer, Cham. doi: 10.1007/978-3-319-44667-7_11

Lainiala, L., Miettinen, A., and Rotkirch, A. (2014). Family Barometer 2014: Family Policy in a Time of Crisis [dataset]. Version 1.0 (2015-04-14). Finnish Social Science Data Archive [distributor]. http://urn.fi/urn:nbn:fi:fsd:T-FSD3005.

Lesthaeghe, R. (2010). The unfolding story of the second demographic transition. Population and Development Review, 36(2): 211-251. doi: 10.1111/j.1728-4457.2010.00328.x

Lesthaeghe, R. (2014). The second demographic transition: A concise overview of its development. Proceedings of the National Academy of Sciences, 111(51): 18112-18115. doi: $10.1073 /$ pnas.1420441111

Liu, J., and Lummaa, V. (2019). Whether to have a second child or not? An integrative approach to women's reproductive decision-making in current China. Evolution and Human Behavior, 40(2): 194-203. doi: 10.1016/j.evolhumbehav.2018.11.004

Lutz, W., Skirbekk, V., and Testa, M. (2006). The low fertility trap hypothesis. Forces that may lead to further postponement and fewer births in Europe. Vienna Yearbook of Population Research, 4: 167-192. doi: 10.1553/populationyearbook2006s167

Melnikas, A. J., and Romero, D. (2020). Ideal age at first birth and associated factors among 
young adults in Greater New York City: Findings from the Social Position and Family Formation Study. Journal of Family Issues, 41(3): 288-311. doi:

\section{$10.1177 / 0192513 X 19875762$}

Miettinen, A. (2015a). Miksi syntyvyys laskee. Suomalaisten lastensaantiin liittyviä toiveita ja odotuksia. [Why the birth rate is falling. Finns' wishes and expectations related to having children]. Perhebarometri 2015. Väestöntutkimuslaitos, Katsauksia E49. Helsinki: Väestöliitto.

Miettinen, A. (2015b). Family Barometer 2015 [dataset]. Version 1.0 (2020-01-22). Finnish Social Science Data Archive [distributor]. http://urn.fi/urn:nbn:fi:fsd:T-FSD3396.

Miettinen, A., Rotkirch, A., Szalma, I., Donno, A., and Tanturri, M. L. (2015c). Increasing childlessness in Europe: Time trends and country differences. Families and Societies. Working Paper Series, 3.

Miettinen, A., and Rotkirch, A. (2008a). Family Barometer 2008: Well-Being and Social Relationships [dataset]. Version 2.0 (2018-06-07). Finnish Social Science Data Archive [distributor]. http://urn.fi/urn:nbn:fi:fsd:T-FSD2792.

Miettinen, A., and Rotkirch, A. (2008b). Milloin on lapsen aika? Lastenhankinnan toiveet ja esteet. [When is it time for a child? Desires and barriers to childcare].

Väestöntutkimuslaitos. Katsauksia E 34/2008 Helsinki: Väestöliitto.

Miettinen, A., and Rotkirch, A. (2010). Family Barometer 2010: Family Policy [dataset]. Version 2.0 (2018-05-22). Finnish Social Science Data Archive [distributor]. http://urn.fi/urn:nbn:fi:fsd:T-FSD2793.

Miller, W. B. (2011). Differences between fertility desires and intentions: implications for theory, research and policy. Vienna Yearbook of Population Research, 9: 75-98. doi: 10.1553/populationyearbook2011s75

Mills, M., and Blossfeld, H.-P. (2013). The Second Demographic Transition Meets Globalization: A Comprehensive Theory to Understand Changes in Family Formation in an Era of Rising Uncertainty. In A. R. Evans \& J. Baxter (Eds.), Negotiating the life course: stability and change in life pathways (pp. 9-33). https://doi.org/10.1007/978-90481-8912-0_2

Morgan, S. P., and Rackin, H. (2010). The correspondence between fertility intentions and behavior in the United States. Population and Development Review, 36(1): 91-118. doi: 10.1111/j.1728-4457.2010.00319.x

Nitsche, N., and Hayford, S. R. (2020). Preferences, partners, and parenthood: Linking early fertility desires, marriage timing, and achieved fertility. Demography 57(6): 1975-2001. 
doi: 10.1007/s13524-020-00927-y

Philipov, D. (2009). Fertility intentions and outcomes: The role of policies to close the gap.

European Journal of Population / Revue Européenne de Démographie, 25(4): 355-361. doi: 10.1007/s10680-009-9202-1

Philipov, D., and Bernardi, L. (2012). Concepts and operationalisation of reproductive decisions implementation in Austria, Germany and Switzerland. Comparative Population Studies, 36(2-3). doi: 10.12765/CPoS-2011-14

Rotkirch, A. (2020). The wish for a child. Vienna Yearbook of Population Research, 18: 113. doi: 10.1553/populationyearbook2020.deb05

Rotkirch, A., Tammisalo, K., Miettinen, A., and Berg, V. (2017). Miksi vanhemmuutta lykätään? Nuorten aikuisten näkemyksiä lastensaannista [Why do young adults postpone parenthood? Young adults' views on having children]. Perhebarometri 2017. Väestöntutkimuslaitos E51. Helsinki: Väestöliitto.

Roustaei, Z., Räisänen, S., Gissler, M., and Heinonen, S. (2019). Fertility rates and the postponement of first births: A descriptive study with Finnish population data. BMJ Open, 9(1): e026336. doi: 10.1136/bmjopen-2018-026336

Rybińska, A. (2020). Trends in intentions to remain childless in the United States. Population Research and Policy Review, 1-12. doi: 10.1007/s11113-020-09604-9

Sobotka, T. (2020). Introduction: The relevance of studying fertility across time and space. Vienna Yearbook of Population Research, 18: 1-24. doi:

10.1553/populationyearbook2020.int01

Sobotka, T., and Beaujouan, É. (2014). Two is best? The persistence of a two-child family ideal in Europe. Population and Development Review, 40(3): 391-419. doi: 10.1111/j.1728-4457.2014.00691.x

StataCorp. (2017). Stata Statistical Software: Release 15. College Station, TX: StataCorp LLC.

Statistics Finland. (2020). Official Statistics of Finland (OSF): Births [e-publication]. ISSN=1798-2413. Helsinki: Statistics Finland [referred: 7.8.2020]. Access method: http://www.stat.fi/til/synt/index_en.html.

Testa, M. R. (2007). Childbearing preferences and family issues in Europe: Evidence from the Eurobarometer 2006 survey. Vienna Yearbook of Population Research, 357-379. doi: 10.1553/populationyearbook2007s357

Testa, M. R. (2012). Family sizes in Europe: Evidence from the 2011 Eurobarometer survey. European Demographic Research Papers 2012, No. 2. Vienna Institute of Demography, 
Austrian Academy of Sciences.

Thomson, E. (2015). Family size preferences. In International Encyclopedia of the Social \& Behavioral Sciences (pp. 805-808). doi: 10.1016/B978-0-08-097086-8.31064-9

Vignoli, D., Bazzani, G., Guetto, R., Minello, A., and Pirani, E. (2020). Uncertainty and narratives of the future: a theoretical framework for contemporary fertility. In R. Schoen (Ed.), Analyzing Contemporary Fertility. The Springer Series on Demographic Methods and Population Analysis (pp. 25-47). Springer, Cham. doi: 10.1007/978-3-030-48519$1 \_3$ 
Table 1. Characteristics of the sample $(n=7,444)$.

\begin{tabular}{|c|c|c|c|c|}
\hline & \multicolumn{2}{|r|}{ Men } & \multicolumn{2}{|r|}{ Women } \\
\hline & $\mathbf{n}$ & $\%(\mathrm{n})$ & $\mathbf{n}$ & $\%(\mathrm{n})$ \\
\hline Age & 2,985 & & 4,459 & \\
\hline $20-24$ & & $8.6(258)$ & & $11.8(524)$ \\
\hline $25-29$ & & $29.7(834)$ & & $28.6(1275)$ \\
\hline $30-34$ & & $23.1(688)$ & & $26.1(1,164)$ \\
\hline $35-39$ & & $21.5(643)$ & & $19.3(859)$ \\
\hline $40-45$ & & $18.8(562)$ & & $14.3(637)$ \\
\hline Number of children & 2,985 & & 4,459 & \\
\hline 0 & & $56.3(1,680)$ & & $53.6(2,391)$ \\
\hline 1 & & $24.7(738)$ & & $26.4(1,175)$ \\
\hline 2 & & $13.6(405)$ & & $13.4(598)$ \\
\hline $3+$ & & $5.4(162)$ & & $6.6(295)$ \\
\hline Partnership status & 2,781 & & 4,374 & \\
\hline Not having a partner & & $36.2(1,007)$ & & $32.0(1,399)$ \\
\hline Having a partner & & $63.8(1,774)$ & & $68.0(2,975)$ \\
\hline Education & 2,948 & & 4,396 & \\
\hline Basic & & $8.2(242)$ & & $3.4(151)$ \\
\hline Secondary & & $38.4(1,132)$ & & $31.0(1,361)$ \\
\hline Lower tertiary & & $33.3(982)$ & & $42.3(1,861)$ \\
\hline Higher tertiary & & $20.1(592)$ & & $23.3(1,023)$ \\
\hline Cohort & 2,985 & & 4,459 & \\
\hline 1970-74 & & $27.3(816)$ & & $22.7(1,010)$ \\
\hline $1975-79$ & & $29.8(890)$ & & $26.6(1,186)$ \\
\hline $1980-84$ & & $21.2(633)$ & & $25.1(1,117)$ \\
\hline $1985-89$ & & 13.7 (409) & & $15.3(680)$ \\
\hline 1990-94 & & $7 / 9(237)$ & & $10.5(466)$ \\
\hline Ideal number of children & 2,985 & & 4,459 & \\
\hline 0 & & $14.7(438)$ & & $15.5(693)$ \\
\hline 1 & & $9.8(292)$ & & $10.4(465)$ \\
\hline 2 & & $51.2(1,527)$ & & $44.9(2,001)$ \\
\hline $3+$ & & $24.4(728)$ & & $29.2(1,300)$ \\
\hline
\end{tabular}



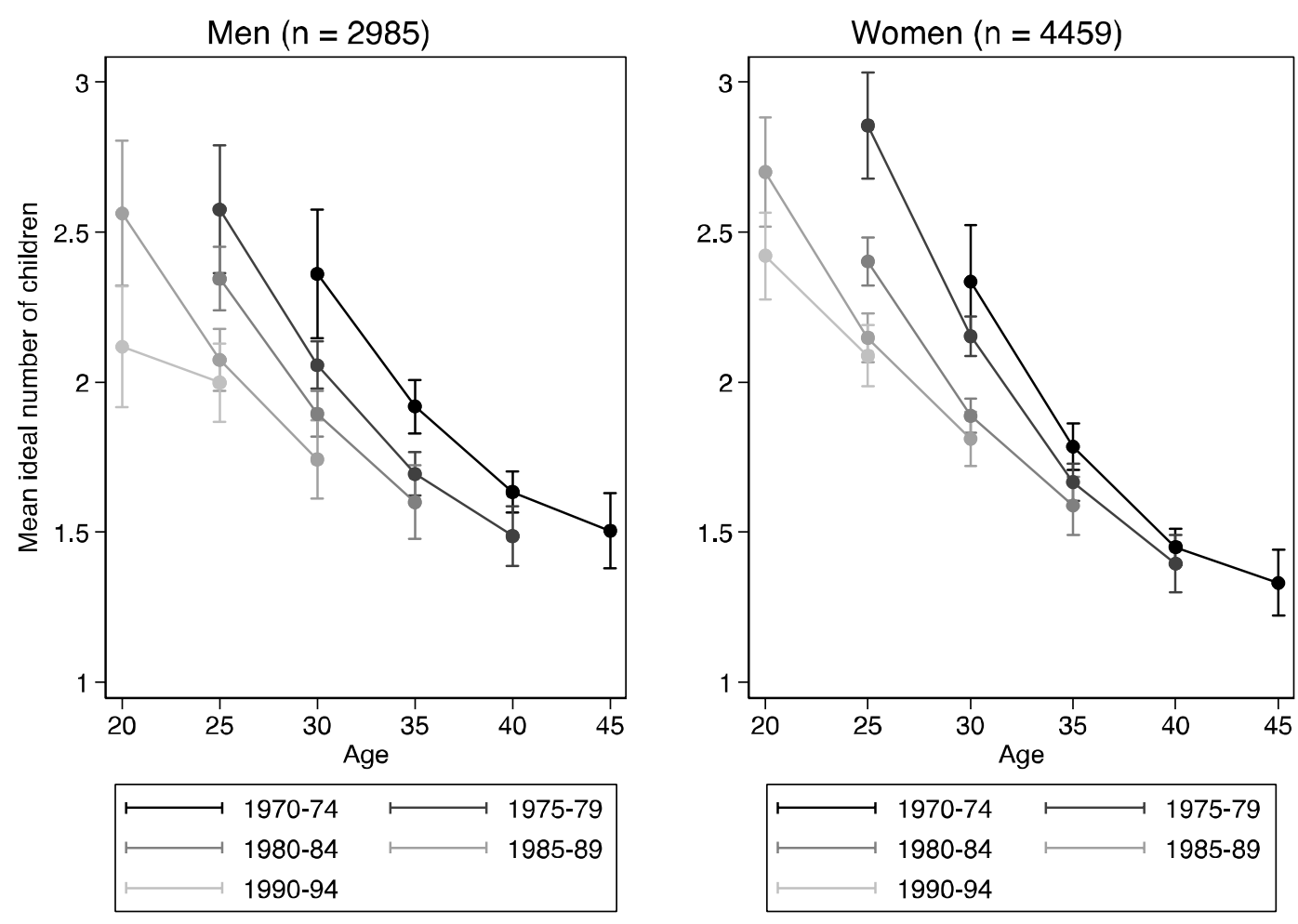

Figure 1. Adjusted predictions of mean ideal number of children by age and birth cohorts for men and women from random-intercept linear regression models adjusted for the number of children $(n=7,444)$. 

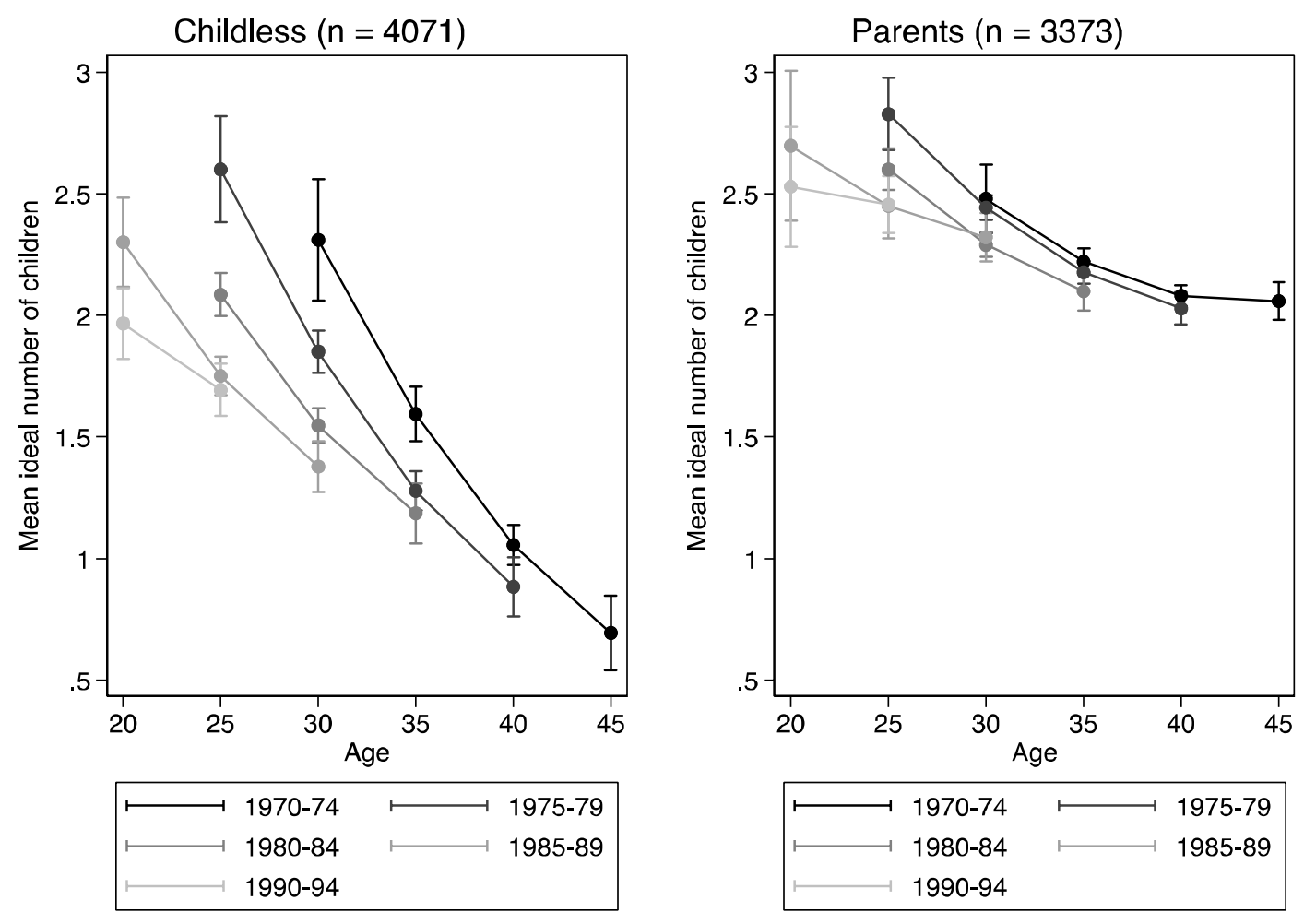

Figure 2. Adjusted predictions of mean ideal number of children by age and birth cohorts for the combined sample of men and women separately among childless people and parents from random-intercept linear regression models $(n=7,444)$. The model for parents was adjusted for the number of children. 


\section{A. Childless young adults: probability of childfree ideals}
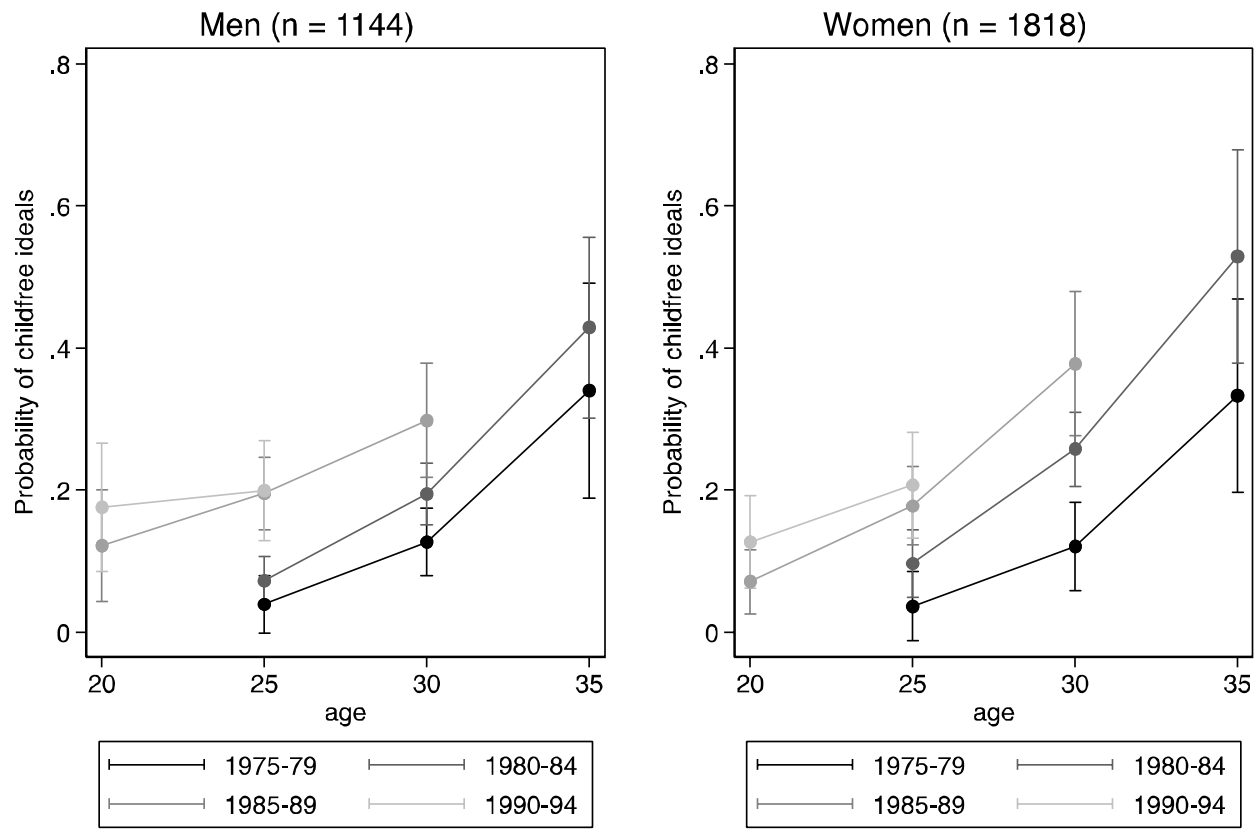

B. Childless young adults: ideal number of children
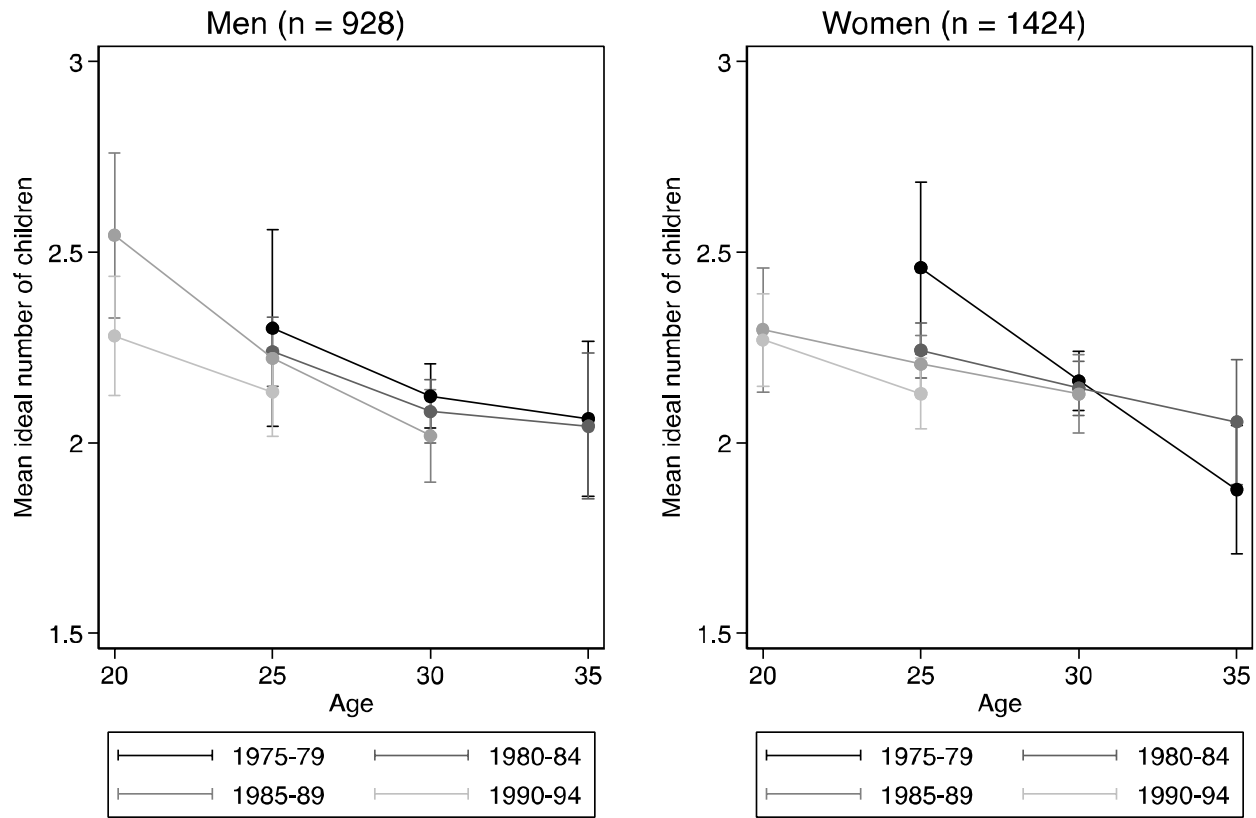

Figure 3. (A) Probability of childfree ideals by age and birth cohort among childless men and women aged 20-35 ( $n=2,962)$ and (B) mean ideal number of children by age and birth cohort among childless men and women aged 20-35 who want to have children $(n=2,499)$. Note. Separate models were tested for men and women. Probability of childfree ideals were tested using random-intercept logistic regression; ideal number of children was tested using random-intercept linear regression. 

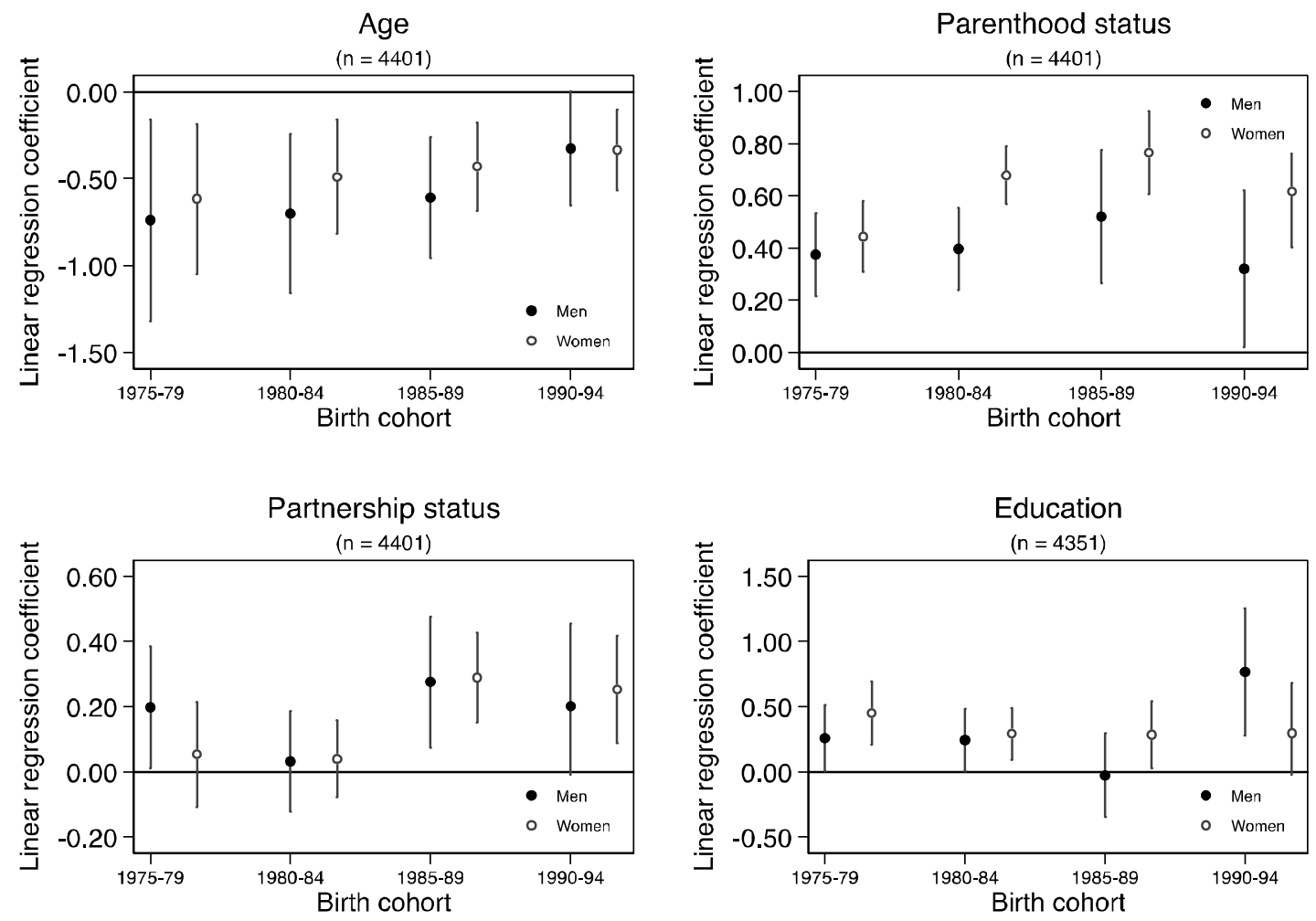

Figure 4. Associations between ideal number of children with age, parenthood status, partnership status, and education by birth cohort for men and women aged 20-35 from four separate random-intercept linear regression models. Estimates are shown in Supplementary Table 7. Note the differences in y-axis ranges. All models include linear and quadratic terms for age, as well as adjusted for partnership status. The models for age, partnership status, and education are also adjusted for the number of children. The three-way interactions between birth cohorts, gender, and the socio-demographic variables of interest were non-significant (all p-values $>0.05$ ). 


\section{SUPPLEMENTARY MATERIALS}

\section{Birth cohort changes in fertility ideals: Evidence from repeated cross-sectional surveys in Finland}

Supplementary Table 1. Proportion of childless vs. parents for men and women by different birth cohorts and age groups $(n=7,444)$.

Supplementary Table 2. Main and interaction effects of age and cohort on ideal number of children among men and women $(n=7,444)$.

Supplementary Table 3. Main and interaction effects of age, parenthood status, and cohort on ideal number of children in the combined sample of men and women $(n=7,444)$.

Supplementary Table 4. The proportion of people wanting children vs. having childfree ideals for childless people and parents from different birth cohorts separately for men and women.

Supplementary Table 5. Main and interaction effects of age and birth cohorts on probability of childfree preferences among childless men and women aged 20-35.

Supplementary Table 6. Main and interaction effects of age and birth cohorts on ideal number of children among childless men and women aged 20-35 who want to have children.

Supplementary Table 7. The associations between ideal number of children with age, parenthood status, partnership status, and education by birth cohorts for childless men and women aged 20-35.

Supplementary Figure 1. Mean ideal number of children by age and birth cohorts for the combined sample of men and women.

Supplementary Figure 2. Probability of having a partner by age and birth cohort for childless men and women $(n=7,155)$. 
Supplementary Table 1. Proportion of childless vs. parents for men and women by different birth cohorts and age groups $(n=7,444)$.

\begin{tabular}{|c|c|c|c|c|c|c|c|}
\hline \multirow[b]{2}{*}{$\begin{array}{l}\text { Birth } \\
\text { cohort }\end{array}$} & \multirow[b]{2}{*}{$\begin{array}{l}\text { Age } \\
\text { group }\end{array}$} & \multicolumn{3}{|c|}{ Men } & \multicolumn{3}{|c|}{ Women } \\
\hline & & $\mathbf{n}$ & $\begin{array}{l}\text { Childless } \\
(\%)\end{array}$ & $\begin{array}{l}\text { Parents } \\
(\%)\end{array}$ & $\mathbf{n}$ & $\begin{array}{l}\text { Childless } \\
(\%)\end{array}$ & $\begin{array}{l}\text { Parents } \\
(\%)\end{array}$ \\
\hline \multirow[t]{5}{*}{$1970-74$} & $20-24$ & NA & & & NA & & \\
\hline & $25-29$ & NA & & & NA & & \\
\hline & $30-34$ & 122 & 36.9 & 63.1 & 145 & 36.6 & 63.5 \\
\hline & $35-39$ & 244 & 37.7 & 62.3 & 311 & 36.3 & 63.7 \\
\hline & $40-45$ & 450 & 42.6 & 57.3 & 554 & 35.4 & 64.6 \\
\hline \multirow[t]{5}{*}{$1975-79$} & $20-24$ & NA & & & NA & & \\
\hline & $25-29$ & 152 & 53.2 & 46.7 & 236 & 49.2 & 50.9 \\
\hline & $30-34$ & 285 & 45.3 & 54.7 & 386 & 37.6 & 62.4 \\
\hline & $35-39$ & 341 & 41.6 & 58.4 & 481 & 42.8 & 57.2 \\
\hline & $40-45$ & 112 & 50.9 & 49.1 & 83 & 31.3 & 68.7 \\
\hline \multirow[t]{5}{*}{$1980-84$} & $20-24$ & 34 & 76.5 & 23.5 & 68 & 82.4 & 17.7 \\
\hline & $25-29$ & 319 & 69.9 & 30.1 & 462 & 65.2 & 34.9 \\
\hline & $30-34$ & 222 & 55.9 & 44.1 & 520 & 51.4 & 48.7 \\
\hline & $35-39$ & 58 & 60.3 & 39.7 & 67 & 46.3 & 53.7 \\
\hline & $40-45$ & 66 & 93.9 & 6.1 & 111 & 94.6 & 5.4 \\
\hline \multirow[t]{5}{*}{ 1985-89 } & $20-24$ & NA & & & NA & & \\
\hline & $25-29$ & 284 & 83.1 & 16.9 & 456 & 70.6 & 29.4 \\
\hline & $30-34$ & 59 & 71.2 & 28.8 & 113 & 65.5 & 34.5 \\
\hline & $35-39$ & NA & & & NA & & \\
\hline & $40-45$ & NA & & & NA & & \\
\hline \multirow[t]{5}{*}{ 1990-94 } & $20-24$ & 158 & 86.7 & 13.3 & 345 & 82.6 & 17.4 \\
\hline & $25-29$ & 79 & 72.2 & 27.9 & 121 & 78.5 & 21.5 \\
\hline & $30-34$ & NA & & & NA & & \\
\hline & $35-39$ & NA & & & NA & & \\
\hline & $40-45$ & NA & & & NA & & \\
\hline
\end{tabular}

Note. $\mathrm{NA}=$ not available in the data. 
Supplementary Table 2. Main and interaction effects of age and cohort on ideal number of children among men and women $(\mathrm{n}=7,444)$.

\begin{tabular}{|c|c|c|c|c|}
\hline & \multicolumn{2}{|c|}{$\operatorname{Men}(n=2985)$} & \multicolumn{2}{|c|}{ Women $(n=4459)$} \\
\hline & $\mathrm{B}(\mathrm{SE})$ & $95 \% \mathrm{CI}$ & $\mathrm{B}(\mathrm{SE})$ & $95 \% \mathrm{CI}$ \\
\hline \multicolumn{5}{|l|}{ Main effects } \\
\hline Age & $-0.83(0.23)$ & $-1.28,-0.38$ & $-1.09(0.20)$ & $-1.48,-0.70$ \\
\hline $\mathrm{Age}^{2}$ & $0.08(0.03)$ & $0.02,0.14$ & $0.11(0.03)$ & $0.06,0.16$ \\
\hline Number of children & $0.45(0.02)$ & $0.41,0.49$ & $0.58(0.01)$ & $0.55,0.61$ \\
\hline \multicolumn{5}{|l|}{ Cohort } \\
\hline 1970-74 & Reference & Reference & Reference & Reference \\
\hline $1975-79$ & $-0.46(0.26)$ & $-0.96,0.04$ & $-0.31(0.23)$ & $-0.76,0.14$ \\
\hline $1980-84$ & $-0.76(0.35)$ & $-1.46,-0.07$ & $-0.95(0.31)$ & $-1.56,-0.33$ \\
\hline $1985-89$ & $-1.15(0.41)$ & $-1.96,-0.34$ & $-1.38(0.36)$ & $-2.08,-0.68$ \\
\hline 1990-94 & $-1.60(0.44)$ & $-2.45,-0.74$ & $-1.66(0.38)$ & $-2.40,-0.92$ \\
\hline \multicolumn{5}{|l|}{ Interaction effects } \\
\hline Age $*$ cohort $1970-74$ & Reference & Reference & Reference & Reference \\
\hline Age $*$ cohort $1975-79$ & $0.08(0.07)$ & $-0.06,0.22$ & $0.06(0.07)$ & $-0.07,0.19$ \\
\hline Age $*$ cohort $1980-84$ & $0.15(0.12)$ & $-0.09,0.39$ & $0.25(0.11)$ & $0.04,0.46$ \\
\hline Age*cohort $1985-89$ & $0.27(0.17)$ & $-0.07,0.60$ & $0.43(0.15)$ & $0.14,0.71$ \\
\hline Age*cohort 1990-94 & $0.64(0.22)$ & $0.20,1.07$ & $0.65(0.19)$ & $0.27,1.02$ \\
\hline Age* cohort (linear trend)* & $0.03(0.02)$ & $-0.02,0.07$ & $0.05(0.02)$ & $0.02,0.09$ \\
\hline
\end{tabular}

Note. $\mathrm{B}=$ unstandardized beta coefficient; $\mathrm{SE}=$ standard error; CI confidence interval.

Estimates in bold are significant at $\mathrm{p}<.05$.

Age is centred at 20 years; a one-unit change in age corresponds to 5 years.

*Linear trend for interaction between age and cohort is analysed in separate models. 
Supplementary Table 3. Main and interaction effects of age, parenthood status, and cohort on ideal number of children in the combined sample of men and women $(n=7,444)$.

\begin{tabular}{|c|c|c|}
\hline & B (SE) & $95 \% \mathrm{CI}$ \\
\hline \multicolumn{3}{|l|}{ Main effects } \\
\hline Age & $-0.95(0.16)$ & $-1.26,-0.64$ \\
\hline $\mathrm{Age}^{2}$ & $0.06(0.02)$ & $0.02,0.10$ \\
\hline Female gender & $-0.03(0.02)$ & $-0.07,0.01$ \\
\hline Being a parent & $-1.08(0.22)$ & $-1.51,-0.65$ \\
\hline \multicolumn{3}{|l|}{ Cohort } \\
\hline 1970-74 & Reference & Reference \\
\hline $1975-79$ & $-0.58(0.24)$ & $-1.04,-0.12$ \\
\hline $1980-84$ & $-1.18(0.28)$ & $-1.74,-0.63$ \\
\hline $1985-89$ & $-1.63(0.31)$ & $-2.24,-1.02$ \\
\hline 1990-94 & $-1.95(0.32)$ & $-2.58,-1.31$ \\
\hline \multicolumn{3}{|l|}{ Interaction effects } \\
\hline Age*cohort $1970-74$ & Reference & Reference \\
\hline Age $*$ cohort $1975-79$ & $0.09(0.07)$ & $-0.04,0.23$ \\
\hline Age*cohort $1980-84$ & $0.25(0.09)$ & $0.06,0.44$ \\
\hline Age*cohort $1985-89$ & $0.38(0.12)$ & $0.14,0.62$ \\
\hline Age*cohort 1990-94 & $0.63(0.16)$ & $0.32,0.93$ \\
\hline Age*childless & Reference & Reference \\
\hline Age*parent & $1.48(0.29)$ & $0.44,0.66$ \\
\hline Parent*cohort 1970-74 & Reference & Reference \\
\hline Parent*cohort 1975-79 & $0.63(0.26)$ & $0.13,1.14$ \\
\hline Parent*cohort 1980-84 & $1.06(0.25)$ & $0.56,1.55$ \\
\hline Parent*cohort 1985-89 & $1.23(0.32)$ & $0.61,1.85$ \\
\hline Parent*cohort 1990-94 & $1.48(0.29)$ & $0.91,2.05$ \\
\hline Age*parent*cohort $1970-74$ & Reference & Reference \\
\hline Age*parent*cohort $1975-79$ & $-0.10(0.07)$ & $-0.25,0.04$ \\
\hline Age*parent*cohort $1980-84$ & $-0.19(0.08)$ & $-0.35,-0.03$ \\
\hline Age*parent*cohort 1985-89 & $-0.16(0.15)$ & $-0.45,0.12$ \\
\hline Age*parent*cohort 1990-94 & $-0.34(0.22)$ & $-0.77,0.09$ \\
\hline
\end{tabular}

Note. $\mathrm{B}=$ unstandardized beta coefficient; $\mathrm{SE}=$ standard error; $\mathrm{CI}$ confidence interval.

Age is centred at 20 years; a one-unit change in age corresponds to 5 years. 
Supplementary Table 4. The proportion of people wanting children vs. having childfree ideals for childless people and parents from different birth cohorts separately for men and women.

\begin{tabular}{|c|c|c|c|c|c|c|c|c|c|c|}
\hline \multirow[b]{2}{*}{ Birth cohorts } & \multicolumn{5}{|c|}{ Men } & \multicolumn{5}{|c|}{ Women } \\
\hline & $1970-74$ & 1975-79 & 1980-84 & 1985-89 & 1990-94 & $1970-74$ & 1975-79 & 1980-84 & 1985-89 & 1990-94 \\
\hline Childless & $\mathrm{n}=329$ & $\mathrm{n}=409$ & $\mathrm{n}=408$ & $\mathrm{n}=340$ & $\mathrm{n}=194$ & $\mathrm{n}=362$ & $\mathrm{n}=493$ & $\mathrm{n}=655$ & $\mathrm{n}=501$ & $\mathrm{n}=380$ \\
\hline Want children & $67.5 \%$ & $71.6 \%$ & $80.9 \%$ & $77.1 \%$ & $80.9 \%$ & $50.8 \%$ & $71.0 \%$ & $76.6 \%$ & $73.7 \%$ & $81.8 \%$ \\
\hline Childfree ideals & $32.5 \%$ & $28.4 \%$ & $19.1 \%$ & $22.9 \%$ & $19.1 \%$ & $49.2 \%$ & $29.0 \%$ & $23.4 \%$ & $26.3 \%$ & $18.2 \%$ \\
\hline Parents & $\mathrm{n}=487$ & $\mathrm{n}=481$ & $\mathrm{n}=225$ & $\mathrm{n}=69$ & $\mathrm{n}=43$ & $n=648$ & $n=693$ & $\mathrm{n}=462$ & $\mathrm{n}=179$ & $\mathrm{n}=86$ \\
\hline Want children & $97.7 \%$ & $99.0 \%$ & $100 \%$ & $98.6 \%$ & $88.4 \%$ & $99.2 \%$ & $99.3 \%$ & $98.5 \%$ & $99.4 \%$ & $100 \%$ \\
\hline Childfree ideals & $2.3 \%$ & $1.0 \%$ & $0 \%$ & $1.5 \%$ & $11.6 \%$ & $0.8 \%$ & $0.7 \%$ & $1.5 \%$ & $0.6 \%$ & $0 \%$ \\
\hline
\end{tabular}


Supplementary Table 5. Main and interaction effects of age and birth cohorts on probability of childfree preferences among childless men and women aged 20-35.

\begin{tabular}{|c|c|c|}
\hline & $\operatorname{Men}(n=1,144)$ & Women $(n=1,818)$ \\
\hline \multicolumn{3}{|l|}{ Main effects } \\
\hline Age & $1.17(0.54,2.51)$ & $1.80(0.91,3.56)$ \\
\hline \multicolumn{3}{|l|}{ Cohort } \\
\hline 1990-1994 & Reference & Reference \\
\hline 1985-1989 & $0.05(0.01,0.38)$ & $0.07(0.01,0.83)$ \\
\hline 1980-1984 & $0.12(0.04,0.36)$ & $0.22(0.06,0.78)$ \\
\hline $1975-1979$ & $0.65(0.25,1.71)$ & $0.52(0.23,1.19)$ \\
\hline \multicolumn{3}{|l|}{ Interaction effects } \\
\hline Age*cohort 1990-1994 & Reference & Reference \\
\hline Age*cohort 1985-1989 & $3.05(1.01,9.16)$ & $2.04(0.65,6.43)$ \\
\hline Age*cohort $1980-1984$ & $2.67(1.10,6.45)$ & $1.82(0.79,4.17)$ \\
\hline Age*cohort 1975-1979 & $1.50(0.60,3.73)$ & $1.57(0.74,3.33)$ \\
\hline Age*cohort (trend)* & $0.84(0.67,1.07)$ & $1.09(0.90,1.30)$ \\
\hline
\end{tabular}

Note. Estimates are odds ratio (95\% confidence intervals) from random-intercept logistic regression models. Estimates in bold are significant at $\mathrm{p}<.05$.

Age is centred at 20 years; a one-unit change in age corresponds to 5 years.

*Trend for interaction between age and cohort is analysed in separate models.

The three-way interactions between age, cohort, and gender are non-significant (all p-values $>0.107)$. 
Supplementary Table 6. Main and interaction effects of age and birth cohorts on ideal number of children among childless men and women aged 20-35 who want to have children.

\begin{tabular}{|c|c|c|c|c|}
\hline & \multicolumn{2}{|l|}{$\operatorname{Men}(\mathbf{n}=928)$} & \multicolumn{2}{|c|}{ Women $(n=1,424)$} \\
\hline & B (SE) & $95 \% \mathrm{CI}$ & B (SE) & $95 \% \mathrm{CI}$ \\
\hline \multicolumn{5}{|l|}{ Main effects } \\
\hline Age & $-0.21(0.12)$ & $-0.45,0.04$ & $-0.15(0.10)$ & $-0.35,0.05$ \\
\hline $\mathrm{Age}^{2}$ & $0.06(0.05)$ & $-0.04,0.16$ & $0.01(0.04)$ & $-0.08,0.09$ \\
\hline \multicolumn{5}{|l|}{ Cohort } \\
\hline 1990-94 & Reference & Reference & Reference & Reference \\
\hline $1985-89$ & $0.32(0.32)$ & $-0.31,0.95$ & $0.50(0.28)$ & $-0.05,1.04$ \\
\hline 1980-84 & $0.24(0.17)$ & $-0.10,0.57$ & $0.08(0.13)$ & $-0.17,0.34$ \\
\hline $1975-79$ & $0.26(0.13)$ & $0.01,0.52$ & $0.03(0.10)$ & $-0.17,0.22$ \\
\hline \multicolumn{5}{|l|}{ Interaction effects } \\
\hline Age $*$ cohort $1990-94$ & Reference & Reference & Reference & Reference \\
\hline Age $*$ cohort 1985-89 & $-0.15(0.21)$ & $-0.57,0.27$ & $-0.17(0.18)$ & $-0.53,0.19$ \\
\hline Age $*$ cohort $1980-84$ & $-0.13(0.16)$ & $-0.44,0.18$ & $0.03(0.13)$ & $-0.22,0.28$ \\
\hline Age*cohort $1975-79$ & $-0.18(0.13)$ & $-0.43,0.08$ & $0.05(0.11)$ & $-0.16,0.26$ \\
\hline Age*cohort (linear trend)* & $0.04(0.04)$ & $-0.04,0.12$ & $0.03(0.03)$ & $-0.03,0.10$ \\
\hline
\end{tabular}

Note. $\mathrm{B}=$ unstandardized beta coefficient; $\mathrm{SE}=$ standard error; $\mathrm{CI}$ confidence interval.

Estimates in bold are significant at $\mathrm{p}<0.05$.

Age is centred at 20 years; a one-unit change in age corresponds to 5 years.

*Linear trend for interaction between age and cohort is analysed in separate models.

The three-way interactions between age, cohort, and gender are non-significant (all p-values

$>0.263)$. 
Supplementary Table 7. The associations between ideal number of children with age, parenthood status, partnership status, and education by birth cohorts for childless men and women aged 20-35.

\begin{tabular}{|c|c|c|}
\hline Birth cohort & Men & Women \\
\hline & Age & \\
\hline $1975-79$ & $-0.74(-1.32,-0.16)$ & $-0.62(-1.05,-0.18)$ \\
\hline $1980-84$ & $-0.70(-1.16,-0.24)$ & $-0.49(-0.82,-0.16)$ \\
\hline $1985-89$ & $-0.61(-0.96,-0.26)$ & $-0.43(-0.68,-0.18)$ \\
\hline \multirow[t]{2}{*}{ 1990-94 } & $-0.33(-0.66,0.00)$ & $-0.33(-0.57,-0.10)$ \\
\hline & Parenthood status & \\
\hline $1975-79$ & $0.38(0.22,0.53)$ & $0.44(0.31,0.58)$ \\
\hline $1980-84$ & $0.40(0.24,0.55)$ & $0.68(0.57,0.79)$ \\
\hline $1985-89$ & $0.52(0.27,0.78)$ & $0.77(0.61,0.92)$ \\
\hline \multirow[t]{2}{*}{ 1990-94 } & $0.32(0.02,0.62)$ & $0.62(0.40,0.83)$ \\
\hline & Partnership status & \\
\hline $1975-79$ & $0.20(0.01,0.39)$ & $0.05(-0.11,0.21)$ \\
\hline $1980-84$ & $0.03(-0.12,0.19)$ & $0.04(-0.08,0.16)$ \\
\hline $1985-89$ & $0.28(0.07,0.48)$ & $0.29(0.15,0.43)$ \\
\hline \multirow[t]{2}{*}{ 1990-94 } & $0.20(-0.05,0.45)$ & $0.25(0.09,0.42)$ \\
\hline & Education & \\
\hline $1975-79$ & $0.26(0.01,0.51)$ & $0.45(0.21,0.69)$ \\
\hline $1980-84$ & $0.24(0.00,0.49)$ & $0.29(0.09,0.49)$ \\
\hline $1985-89$ & $-0.03(-0.35,0.29)$ & $0.28(0.03,0.54)$ \\
\hline 1990-94 & $0.77(0.28,1.25)$ & $0.30(-0.09,0.68)$ \\
\hline
\end{tabular}

Note. Estimates are unstandardized regression coefficients (95\% confidence intervals) from random-intercept linear regression models. Age, parenthood status, partnership status, and education are analysed in separate models. All models include linear and quadratic terms for age, as well as adjusted for partnership status. The models for age, partnership status, and education are also adjusted for the number of children. Age is centred at 20 years; a one-unit change in age corresponds to 5 years. A one-unit change in education corresponds to change from basic to upper tertiary education. 


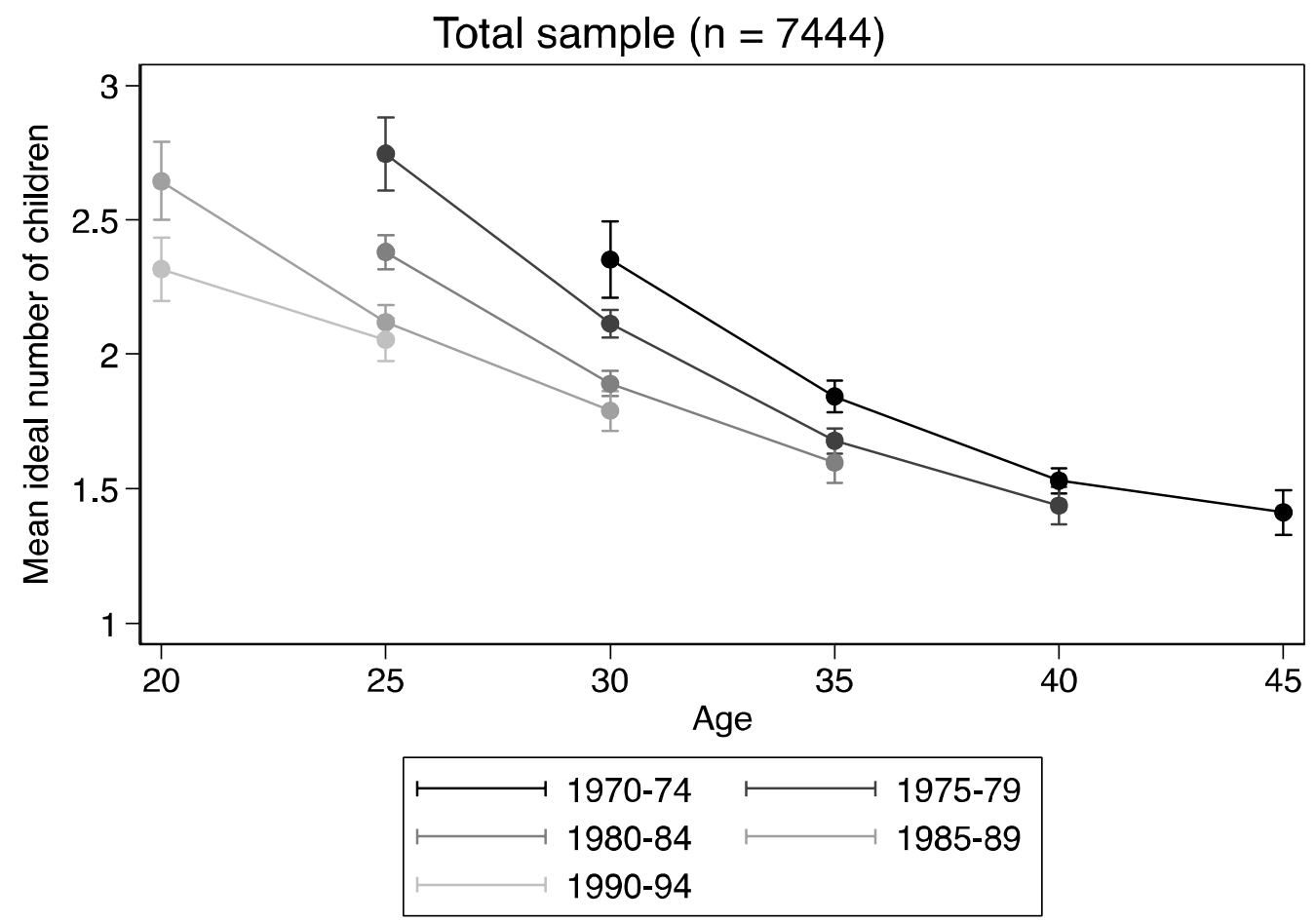

Supplementary Figure 1. Mean ideal number of children by age and birth cohorts for the combined sample of men and women. 

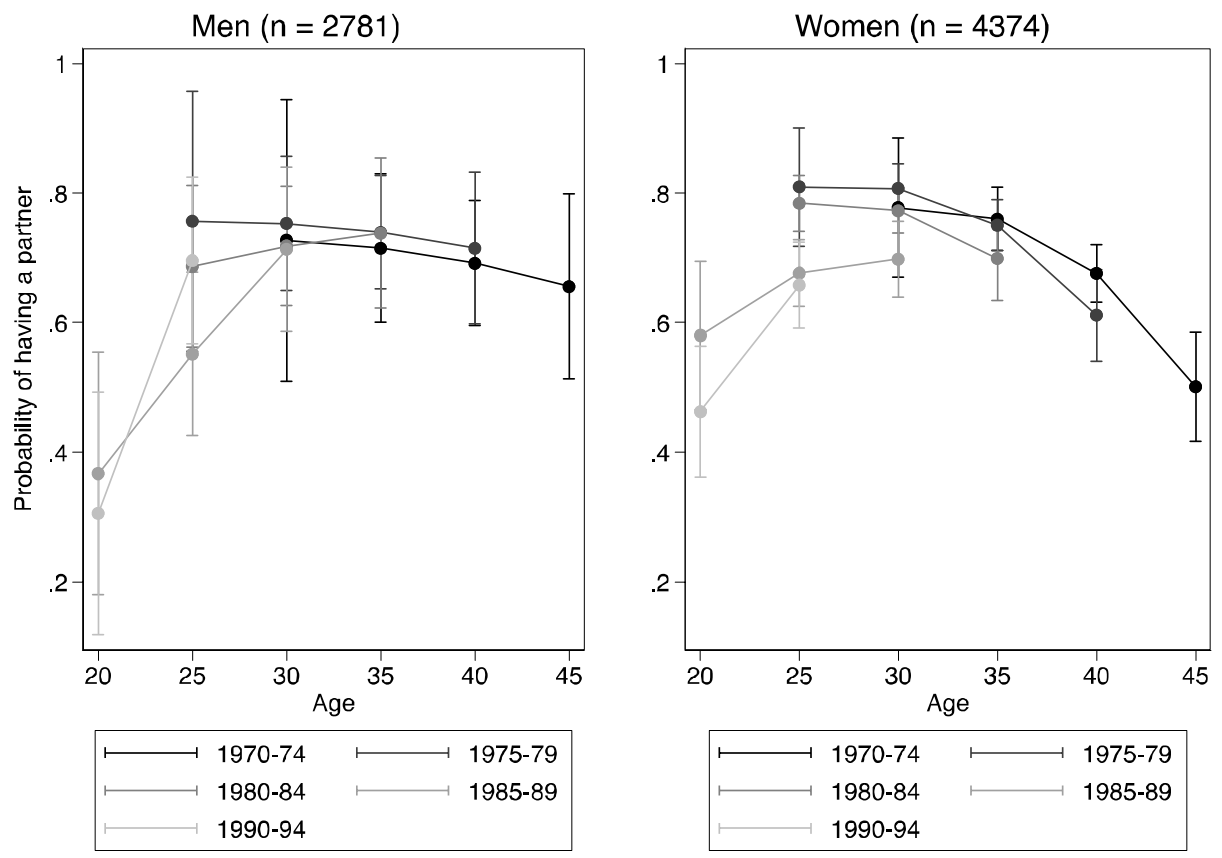

Supplementary Figure 2. Probability of having a partner by age and birth cohort for childless men and women $(n=7,155)$. 